when being asked to consider taking a patient under Section 37 of the Mental Health Act.

To give two brief examples, one of a relatively minor nature: a man with a past history some years ago of aggressive hypomanic states requiring inpatient treatment, had on this occasion, been aggressive to his wife as she would not give him the keys of the car. He had already lost his licence for driving under the influence of drink. When seen his mental state was quite settled. However, it would have been desirable to have had access to his wife's statement to the police at the time of the offence to get a clear picture of his mental state at the time.

In a more serious case, there was a prisoner who had assaulted another man with an axe at a party, claiming he had been provoked with a row over a girlfriend. There was also a question as to how much he had had to drink at the time. Since the incident he had developed a reactive paranoid psychotic state. To make a meaningful evaluation it would seem vital to have access to the eyewitness's account of his state at the time.

If asked by a solicitor to prepare a report for their client, one would be given access to all the relevant depositions. However, when routinely seeing patients on remand at the request of the Prison Medical Officer these documents are not usually available.

I feel that the Royal College of Psychiatrists should pursue this matter by insisting that the Prison Medical Officers and the requested visiting psychiatrists are provided with the full background details of any offence. I feel sure that members of the College placed in similar circumstances would agree with this view.

Claybury Hospital

R. LUCAS

Woodford Green, Essex IG8 $8 B Y$

\section{Psychiatric day hospitals}

DEAR SIRS

The psychiatric day hospitals have been providing a service for over 40 years. It has been said that the only thing that day hospitals have in common is that they are entirely different (DHSS, 1969).

There are conflicting reports on how effective day care can be and for what type of patient, and there have been few conclusive findings showing any specific factors that would lead to a better service for patients attending day hospitals. It is accepted that it is best to separate psychogeriatric patients from younger patients and to separate the neurotic population from the psychotic and long-term younger population (Farid, 1988; Lancet, 1987).

A practical issue that has not been discussed is the administrative responsibility for day hospitals. Some day hospitals are led by a nominated consultant psychiatrist who takes responsibility for all patients attending the hospital. Other colleagues refer patients to him and he usually assumes full responsibility until their discharge from the day hospital. In practice, what usually happens is that the consultant in charge uses most of the facilities for his own patients and other consultants are usually reluctant to refer their patients for someone else to assume responsibility and prescribe treatment for them.

The other extreme is for all consultants to provide and prescribe treatment for their clients attending day hospitals resulting in confusion of the existing day hospital staff as to who is actually in charge and how to reconcile the different models of treatment and different clients attending for the same treatment facility at the same time.

I wonder whether anyone has looked at how important different models of leadership can be in effecting success, or lack of it, in day hospitals, or whether people have thought of a practical and innovative solution for this problem.

\section{New Cross Hospital}

B. T. FARID

\section{Wolverhampton WV10 0QP}

References

Department of Health and Social Security (1969) $A$ Pilot Study of Patients attending the Day Hospitals. Statistical Report No. 7. London: HMSO.

FARID, B. T. \& HIRONS, J. M. (1988) Psychiatric day hospitals. The Lancet, $i, 127$.

EDITORIAL (1987) Psychiatric day hospitals. The Lancet, ii, 1184-1185.

\section{The election of College representatives}

DeAr SIRS

Another wadge of ballot papers for College posts has recently tumbled through my letter box. I am dismayed to see that the accompanying biographical notes are, as usual, uniformly dull. Moreover, they do not help me distinguish which candidate would be most suited to the job. All are eminent men who have served on numerous committees and have large numbers of publications to their names. Given the very similar descriptions of all the candidates, how am I, as an ordinary member of the College, going to choose the best man, or woman, for the job? As it stands, my choice is determined by such chance factors as sex (I vote for any woman on principle), having read an interesting paper by them or having heard a complimentary rumour about them on the grapevine.

Surely this is no basis for making important decisions about College representatives? Could we not hear from these people why they believe they should get the job, what particular talents they would bring to it and what they intend to do if elected?

St Mary Abbots Hospital

Camilla M. Haw 